\title{
Instability of the Liquid Metal-Pattern Interface in the Lost Foam Casting of Aluminum Alloys
}

\begin{abstract}
W.D. GRIFFITHS and M.J. AINSWORTH
The nature of the liquid metal-pattern interface during mold filling in the Lost Foam casting of aluminum alloys was investigated using real-time X-ray radiography for both normal expanded polystyrene, and brominated polystyrene foam patterns. Filling the pattern under the action of gravity from above or below had little effect on properties, both cases resulting in a large scatter of tensile strength values, (quantified by their Weibull Modulus). Countergravity filling at different velocities demonstrated that the least scatter of tensile strength values (highest Weibull Modulus) was associated with the slowest filling, when a planar liquid metal-pattern interface occurred. Real-time X-ray radiography showed that the advancing liquid metal front became unstable above a certain critical velocity, leading to the entrainment of the degrading pattern material and associated defects. It has been suggested that the transition of the advancing liquid metal-pattern interface into an unstable regime may be a result of Saffman-Taylor Instability.
\end{abstract}

DOI: $10.1007 / \mathrm{s} 11661-016-3461-3$

(C) The Author(s) 2016. This article is published with open access at Springerlink.com

\section{INTRODUCTION}

IN Lost Foam casting a foamed polymer pattern, usually polystyrene, (EPS), is placed in a mold made from loose dry silica sand and compacted by vibration. The mold is then filled and the pattern degraded in situ during mold filling by the heat of the liquid metal. The process gives great flexibility of design but is also prone to numerous types of defects, such as entrainment of the degrading pattern material, (leading to porosity), folds and laps, and misrun due to the liquid metal losing heat as it slowly fills the mold, causing premature solidification. The work reported here was aimed at improving understanding of the nature of the metal-pattern interface, in order to try to reduce defects associated with entrainment of the degrading pattern.

It is generally understood that the interface consists of a mixture of gaseous and liquid polymer byproducts and several investigations have been carried out into its nature. Shivkumar et al., ${ }^{[1]}$ placed glass plates against the pattern and observed a gas layer between the metal and the foam of about $5 \mathrm{~mm}$ in thickness, at a temperature of about $1023 \mathrm{~K}\left(750{ }^{\circ} \mathrm{C}\right.$ ). (But as the normal pattern coating is permeable, the thickness of the gas layer was presumably increased due to the use of an impermeable glass plate.) It was reported that as liquid metal temperature increased, so did gap thickness, and Polymethlymethacrylate (PMMA) foam patterns were

W.D. GRIFFITHS, Senior Lecturer, is with the School of Metallurgy and Materials, College of Engineering and Physical Sciences, University of Birmingham, Edgbaston, Birmingham B15 2TT, UK. Contact e-mail: w.d.griffiths@bham.ac.uk M.J. AINSWORTH, Product Manager, formerly with the Gemco Engineers B.V., Science Park Eindhoven 5053, 5692 EB Son, The Netherlands, is now Operations Manager with Saudi Mechanical Industries Co., Riyadh, Saudi Arabia.

Manuscript submitted on June 25, 2015.

Article published online April 12, 2016 observed to produce a thicker gas layer than expanded polystyrene (EPS) patterns. Yao and Shivkumar ${ }^{[2]}$ also proposed that a gas layer would build up in front of the advancing liquid metal, with the amount of gas increasing with increasing metal temperature, and increased with the use of PMMA compared to EPS, but the thickness of the gas layer in the case of Al was described by them as "negligible." Shivkumar, ${ }^{[3]}$ in a model of temperature loss occurring during the Lost Foam casting of $\mathrm{Al}$, described the interface as being a layer of 1 to $2 \mathrm{~mm}$ in thickness, and formed predominantly of gas, but also containing viscous liquid residues from the foam degradation. The gas was assumed to be a mixture of styrene, occurring not only as a monomer, but also as dimers, trimers, and tetramers. However, the model indicated that a continuous gas layer should not be expected to exist, as even a layer of gas of $0.5 \mathrm{~mm}$ in thickness interposed too great a barrier to interfacial heat transfer, and in the final model they were obliged to assume no gas at the metal-pattern interface.

Yang et al ${ }^{[4]}$ described the interface of the pattern and the liquid $\mathrm{Al}$ as consisting of two parts, a thermally affected but undegraded zone, 1 to $3 \mathrm{~mm}$ in thickness, adjacent to the pattern, and a zone of pattern degradation byproducts, also 1 to $3 \mathrm{~mm}$ in thickness, adjacent to the advancing liquid Al. For the case of casting of $\mathrm{Al}$, it was determined that the interfacial pressure was in the region of 200 to $500 \mathrm{~Pa}$, (much lower than the pressures of 11 to $26 \mathrm{kPa}$ found in the case of cast iron), and it was deduced that the interface should therefore largely consist of liquid degradation byproducts, which would be required to be removed through the permeable pattern coating.

Warner et $a l .{ }^{[5]}$ and Molibog and Littleton, ${ }^{[6]}$ described the interface between the foam pattern and the liquid metal as a kinetic zone, a gap or interface containing both liquid and gaseous byproducts from the foam degradation process, mixed with air. Littleton 
et $a l .{ }^{[7]}$ showed how the extent of the kinetic zone varied according to the pouring temperature and alloy cast (i.e., $\mathrm{Al}$ or $\mathrm{Fe}$ alloys), and the foam type, (EPS or PMMA). Sun et al. ${ }^{[8]}$ used real-time X-ray imaging to examine the filling of Lost Foam patterns of variable density and degree of bead fusion, and varying coating permeability. It was found that the liquid metal front developed coarse fingers as it passed through regions of the pattern having low bead fusion, but displayed a planoconvex front when filling patterns of normal bead fusion. Sands and Shivkumar ${ }^{[9]}$ proposed this kinetic zone to be a largely gaseous layer of between 1 to $3 \mathrm{~mm}$, with the gap thickness affected by both coating and mold permeability. It was also observed that polydispersity, (the variation in molecular weight of a polymer), affected the rate of gas production.

To summarize, this earlier work varied considerably in its conclusions, with researchers suggesting different thicknesses of the interfacial gap, and containing either largely vapor or largely liquid foam pattern degradation byproducts.

More detailed work has been aimed at understanding how the degradation of the pattern at the interface can lead to defects. Sun et al. ${ }^{[10]}$ proposed that liquid polystyrene produced at the pattern-metal interface would wet the permeable coating surface and then be wicked into it. With increasing temperature of the liquid polystyrene degradation byproducts, and increasing time, the molecular weight of the liquid polystyrene would be reduced, its viscosity would be reduced, and wetting and wicking would occur more readily, (especially with increased permeability of the coating). However, these wetting and wicking processes would occur after the mold had been filled. Zhao et al. ${ }^{[11]}$ proposed a different mechanism for the removal of the liquid polystyrene, in which the liquid degradation byproducts formed globules adhering to the coating surface, with heat from the surrounding liquid metal creating a gaseous (and therefore insulating) layer

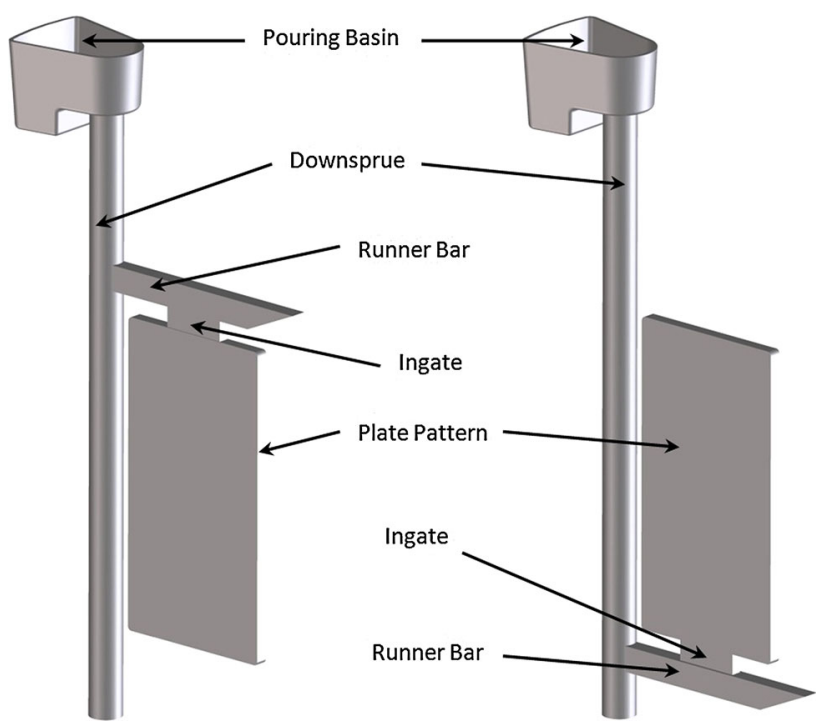

Fig. 1-Diagram of the top- and bottom-gated castings, filled under the action of gravity. between the metal and the globule, preventing its rapid vaporization, (essentially the Leidenfrost Phenomenon or film boiling). Passage of the vapor byproduct through the permeable coating would only occur in the thin annulus of exposed coating around each liquid globule. The polystyrene liquid globules would therefore only slowly reduce in size, and if the casting solidified before they were removed, surface defects would be formed. Both explanations seem to be partly true, with a critical molecular weight needed for wetting of, and wicking into, a coating. Griffiths and Davies ${ }^{[12]}$ determined the values of this critical molecular weight, and how it varied with coating permeability.

Barone and Caulke ${ }^{[13,14]}$ identified several mechanisms by which the foam pattern degraded during mold filling, namely, (i). a contact mode, (ii). an ablation mode, ${ }^{[15]}$ (described as the usual method of foam degradation), (iii). a collapse mode, and (iv). a foam engulfment mode. They proposed ${ }^{[14]}$ that a thin "decomposition layer," consisting of a foam containing a mixture of liquid and gas byproducts was formed at the interface, of about $150 \mu \mathrm{m}$ in thickness. Elsewhere ${ }^{[15]}$ the decomposition layer was proposed to be around $100 \mu \mathrm{m}$ in depth, and contain 99 pet gas by volume, although this would seem to contradict other workers, who reported greater amounts of liquid degradation byproducts. Caulk ${ }^{[16]}$ also identified circumstances under which a gas gap, (the "gap mode"), could form between the metal and the pattern, due to vaporization of the polymer. It was proposed that the gap width could be between 5 and $20 \mathrm{~mm}$, which seems excessive, although consistent with their neutron radiography observations of the interface. It was suggested that these pattern degradation byproducts usually traveled normal to the advancing liquid metal front and passed out through the coating. However, when the liquid metal penetrated into the connected interbead porosity in the pattern (perhaps due to poor bead fusion ${ }^{[13]}$, this could lead to engulfment of parts of the degrading foam pattern. ${ }^{[15,17]}$

Research to date has therefore generally understood the metal-pattern interface in terms of a gap between the liquid metal and the polymer foam pattern, filled with different ratios of gaseous and liquid degradation byproducts. This was based on assumptions that the structure of the interface is largely governed by the transfer of heat from the liquid metal through the material of the interface, into the foam pattern, resulting in its breakdown. However, an alternative view of the interface in Lost Foam casting of Al may be proposed, where the interface can be seen as being between two fluids, a viscous low-density fluid, (the mixed gaseous and liquid polymer byproducts), and a lower-viscosity, higher-density liquid, (the liquid metal). This interface could be prone to the development of an instability which could affect the interface behavior. ${ }^{[18]}$

Three types of interfacial instability can commonly occur at fluid-fluid interfaces. Firstly, Rayleigh-Taylor Instability occurs at the interface of two fluids of different densities, when their interface is accelerated in a direction normal to the interface. ${ }^{[19]}$ This occurs, for example, when a denser fluid overlies a less-dense fluid, and their interface is accelerated downwards by the 


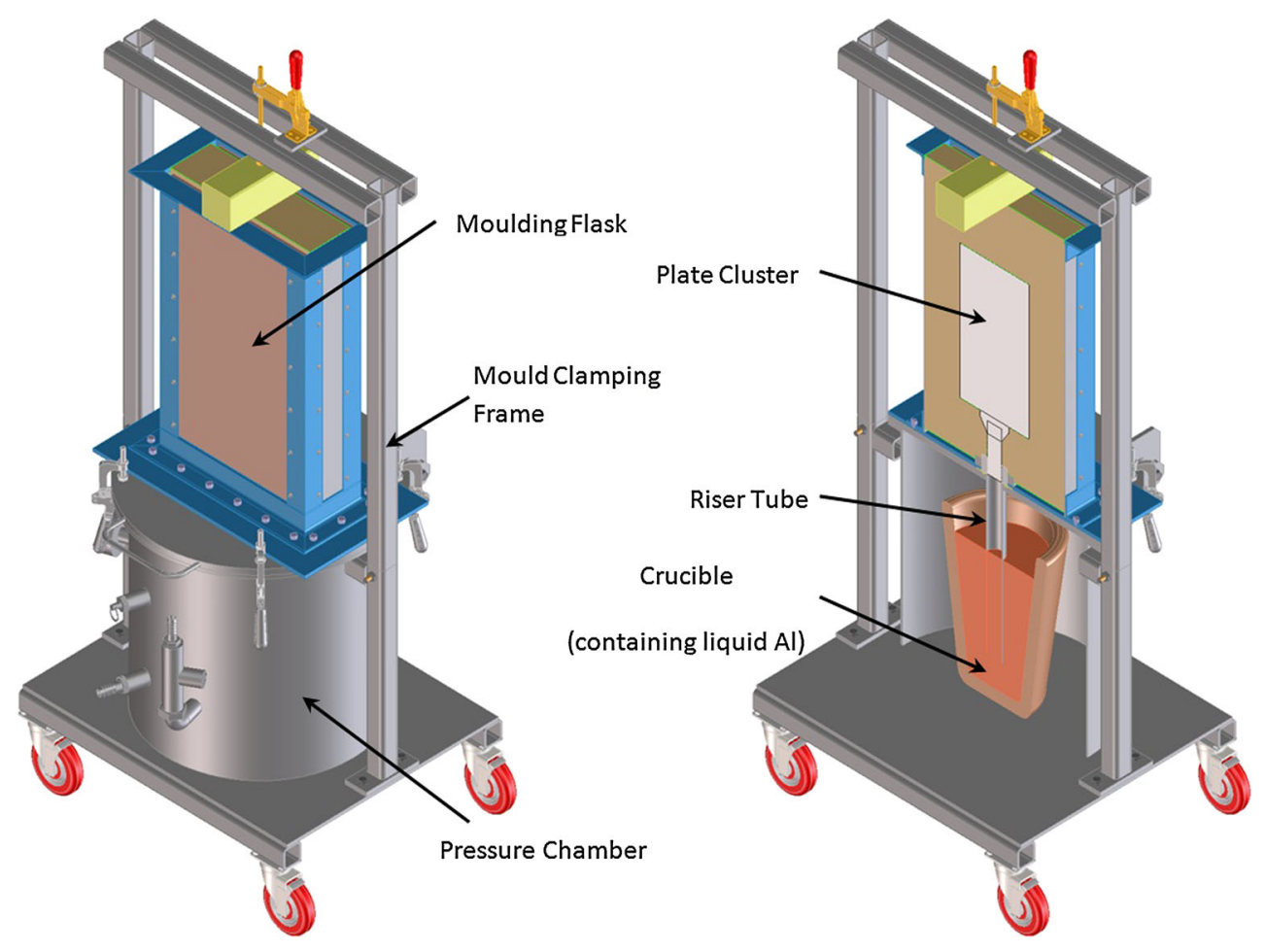

Fig. 2-Diagram of the countergravity casting arrangement.

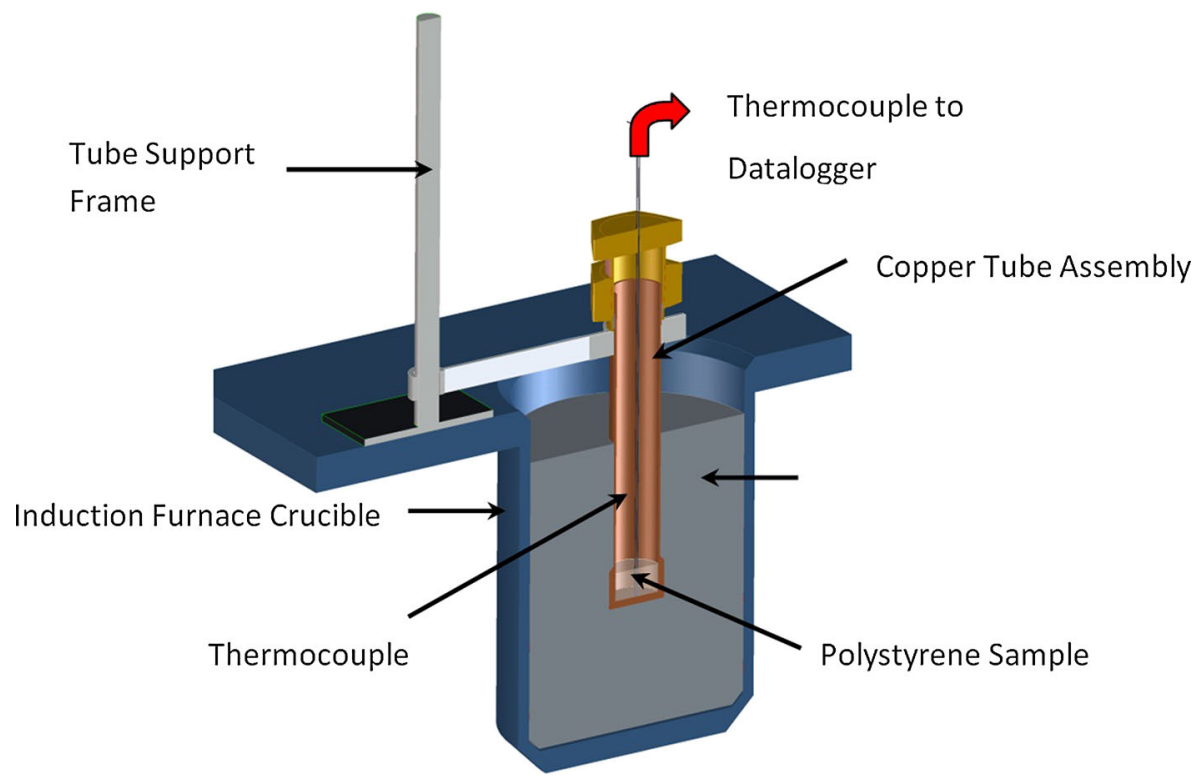

Fig. 3-Diagram showing the experimental arrangement used to degrade foamed polymer samples.

action of gravity, resulting in an unstable interface and mixing between the two fluids. Secondly, KelvinHelmholtz Instability occurs at the interface between fluids of different densities, experiencing a motion parallel to their interface, ${ }^{[20,21]}$ e.g., waves occurring on a body of water due to the action of wind. Thirdly, Saffman-Taylor Instability occurs at the interface between two fluids of different densities and different viscosities, when the interface between a high density, low-viscosity liquid, and a low-density, high-viscosity liquid, is accelerated in the direction normal to the interface. ${ }^{[22]}$

During development of the commercial casting simulation software Flow-3D, Hirt suggested that when the liquid metal enters the mold from above then the interface, being accelerated downwards through the foam pattern by the action of gravity, should lead to Rayleigh-Taylor Instability. It was further observed that if the casting was filled from below, in a 

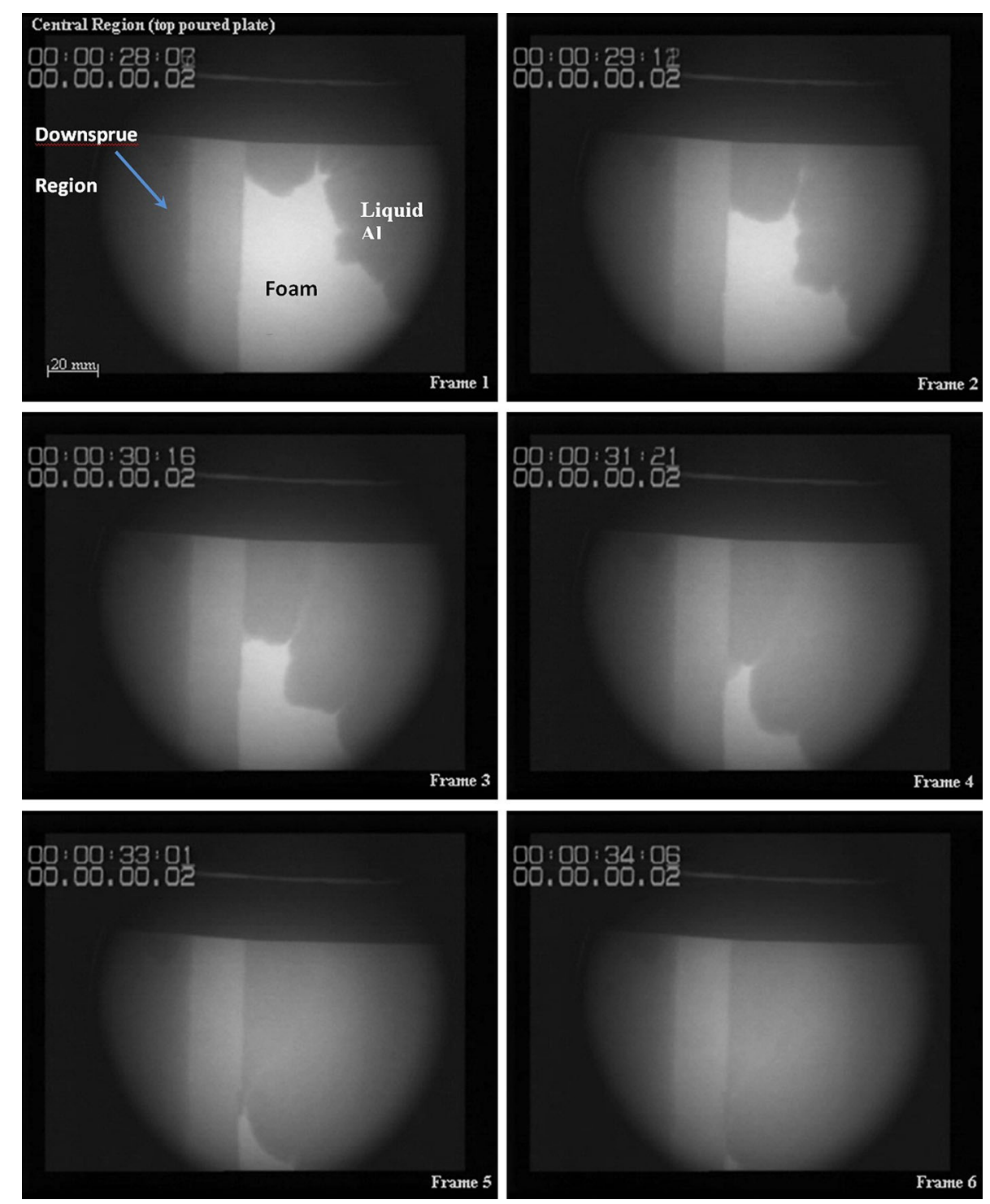

Fig. 4-Real-time X-ray images showing the morphology of the advancing liquid metal front, in an EPS pattern, when top-gated and poured under the action of gravity.

countergravity fashion, then the action of gravity should smooth out any irregularities in the interface, which would presumably benefit the quality of the casting. ${ }^{[23]}$

The work reported here was aimed at investigating the advantages of countergravity filling of Lost Foam molds with Al alloy, compared to filling the mold from above, and involved an investigation of the nature of the foam pattern-liquid metal interface using real-time X-ray radiography. The results have been interpreted to determine if an interfacial instability is likely to occur.

\section{EXPERIMENTAL PROCEDURE}

\section{A. Top-Poured Cast Plates}

Vertically oriented foam plate patterns were cast to determine the effect of filling from the top compared to filling from the bottom on the properties of Al alloy Lost Foam castings. The foam plate patterns had dimensions $360 \mathrm{~mm}$ in length, $200 \mathrm{~mm}$ in width, and $15 \mathrm{~mm}$ in thickness, and were attached to conventional square section running systems with ingate areas of 10.4 $\mathrm{cm}^{2}$. The running system was arranged so as to introduce the liquid metal at either the top or bottom of the plates, (see Figure 1). The mean pattern density was $30 \mathrm{~kg} \mathrm{~m}^{-3}$ and the polystyrene plate patterns were coated with a commercial water-based slurry coating, which was allowed to dry, before being placed in a molding box of internal dimensions $0.45 \times 0.11 \times 0.83$ $\mathrm{m}$. The pattern was supported by loose unbonded silica sand, compacted by vibration.

The plates were cast at $1053 \mathrm{~K}\left(780^{\circ} \mathrm{C}\right)$ with a $\mathrm{Sr}$ pre-modified Al-1 wt pct Si alloy, with a $200-\mathrm{mm}$ head height between the bottom of the pouring basin and the upper edge of the plates. The filling of the castings was carried out within a $160-\mathrm{keV}$ real-time X-ray radiography instrument, to observe the flow pattern of the metal as it filled the mold. 

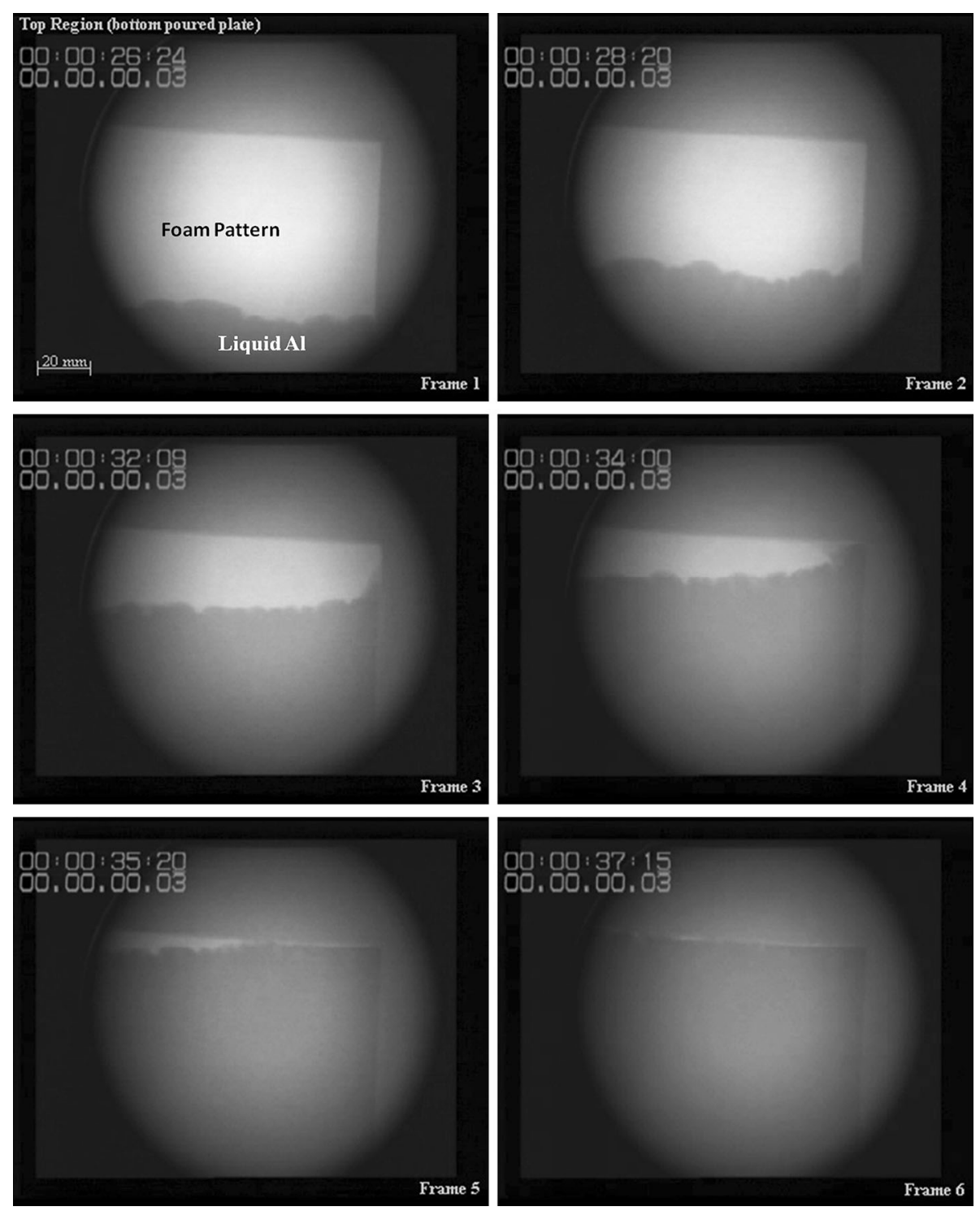

Fig. 5-Real-time X-ray images showing the morphology of the advancing liquid metal front, in an EPS pattern, when bottom-gated and poured under the action of gravity.

The cast plates were sectioned to obtain eight horizontally oriented tensile test bars from each plate, each having a gage length of $60 \mathrm{~mm}$ and diameter in the gage length of $10 \mathrm{~mm}$, which were tested using a Losenhausen Universal Testing Machine at a strain rate of $1 \mathrm{~mm} \mathrm{~min}{ }^{-1}$. The tensile property results obtained were normalized against the maximum value of (engineering) tensile strength in the dataset, and then analyzed using a Weibull statistical approach, to show how filling of the mold influenced the distribution of mechanical properties and the quality of the castings produced. ${ }^{[2]}$ The two-parameter Weibull equation is shown in Eq. [1]

$$
P=1-\exp \left(-\left(\frac{\sigma}{\sigma_{0}}\right)^{m}\right)
$$

In this equation, $P$ is the probability of failure at a tensile stress of $\sigma$. The Weibull parameters used to characterize the material properties are the Weibull modulus, $\mathrm{m}$, and the scale parameter $\sigma_{0}$. The Weibull modulus shows the scatter of properties, with a higher Weibull modulus indicating a narrower spread of properties and in this application, a casting operation associated with low numbers of defects in the final casting and greater reproducibility of properties. The scale parameter $\sigma_{0}$ is obtained from the intercept of the Weibull plot on the $y$-axis, where $y=\left(-m \ln \sigma_{0}\right)$, or $\sigma_{0}=\exp (y /-m)$, and represents the tensile strength below which $63.2 \mathrm{pct}$ of the samples failed.

Taking the logarithm of equation Eq. [1] twice gives

$$
\ln \left[\ln \left(\frac{1}{1-P_{f, n}}\right)\right]=m \ln \sigma_{n}-m \ln \sigma_{0} .
$$

The Weibull modulus $\mathrm{m}$ is therefore the gradient of a plot of $\ln \left(\ln \left(1 /\left(1-P_{f, n}\right)\right)\right)$ against measured tensile 


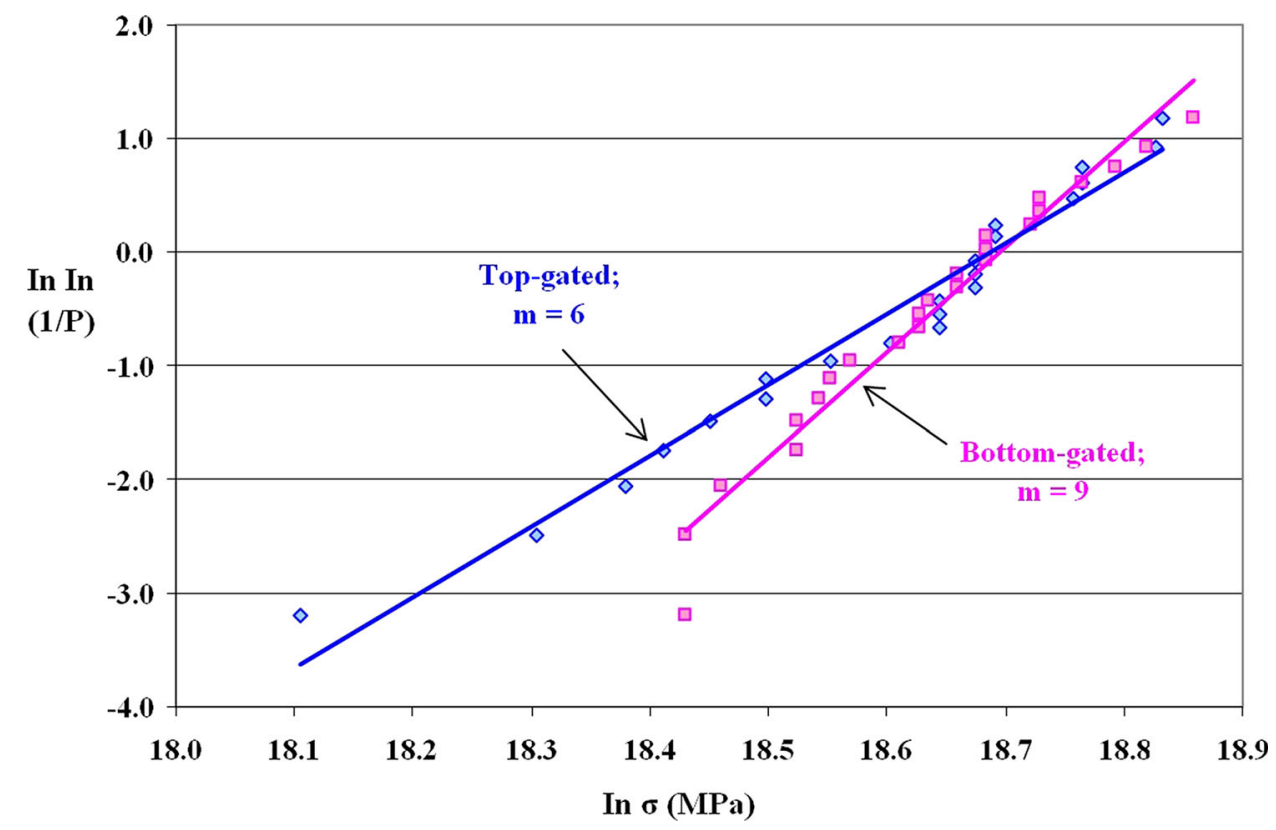

Fig. 6 - Comparison of Weibull Moduli for the top- and bottom-gated plates cast under the action of gravity.

strength, $\left(\ln \left(\sigma_{n}\right)\right.$, where $P_{f, n}$ is a measure of the probability of failure.

\section{B. Countergravity Cast Plates}

In a second series of experiments, similar vertically oriented foamed polystyrene plate patterns were cast, using a countergravity filling arrangement. In this case, the foamed patterns had dimensions of $440 \times 180 \times 10 \mathrm{~mm}$ and were mounted in a molding box placed directly over a cylindrical steel chamber containing a resistance-heated coil. The mold was fitted with a steel riser tube of internal diameter $40 \mathrm{~mm}$, which passed down into the steel chamber and into a crucible containing an $8 \mathrm{~kg}$ melt of 2L99 Al alloy, (Al-7 wt pct $\mathrm{Si}-0.3 \mathrm{wt}$ pct $\mathrm{Mg}$ ). When the liquid metal in the crucible had reached $1058 \mathrm{~K}\left(785^{\circ} \mathrm{C}\right)$, compressed air, within a pressure range of 24 to $69 \mathrm{kPa}$, (equivalent to an overpressure of 0.23 to 0.67 bar), was introduced into the steel chamber, which forced the liquid metal up the riser tube and into the mold at varying velocities. Once the liquid metal had filled the mold, or the liquid metal had stopped moving, a valve was closed to prevent the metal from draining back into the crucible during solidification. These countergravity-filled molds were also cast in the real-time X-ray instrument so that the metal-foam interface could be observed during mold filling, and the velocity with which the plate pattern was filled could be measured. Figure 2 shows a diagram of the casting arrangement.

To characterize the properties of the countergravity cast plates, 23 horizontally oriented tensile test bars were taken from the plates having dimensions of $60 \mathrm{~mm}$ gage length and $6.7 \mathrm{~mm}$ diameter in the gage length. The tensile properties obtained were again normalized against the maximum value in the dataset, and a Weibull analysis was carried out.
C. The Effect of Thermal Degradation of the Polymer Pattern on the Molecular Weight and Viscosity of the Liquid Degradation Byproducts

In order to estimate the viscosity of the liquid polymer degradation byproducts in the liquid metal-foam pattern interface during mold filling, samples of the pattern material, of mass about 0.1 to $0.2 \mathrm{~g}$, were subjected to varying amounts of thermal degradation. The polystyrene was placed in the base of copper tubes, (of internal diameter $21 \mathrm{~mm}$, length $120 \mathrm{~mm}$, and wall thickness 1 $\mathrm{mm}$ ), and plunged into a melt of liquid Al held at 1053 $\mathrm{K}\left(780^{\circ} \mathrm{C}\right)$, to a depth of $70 \mathrm{~mm}$. The temperature at the base of the copper tubes where the polystyrene samples sat was monitored using a $0.5-\mathrm{mm}$ diameter Type-K thermocouple, as shown in Figure 3. The high thermal conductivity of the copper tube meant that the foam pattern inside should have experienced a rapid temperature increase, analogous to what would be experienced in the mold as the liquid metal advanced through the degrading pattern.

Once the temperature of the thermocouple in the copper tube reached the required temperature, [up to $873 \mathrm{~K}$ $\left.\left(600{ }^{\circ} \mathrm{C}\right)\right]$, the tube was then removed from the melt and quenched in cold water to preserve the degraded pattern material it contained. The Weight Average molecular weight of the degraded polymer pattern material was then measured by Gel Permeation Chromatography, (at RAPRA, Shrewsbury). The apparent viscosity, (dynamic viscosity at zero shear), of the polymer in the liquid metal-pattern interface was then estimated using Eq. [3], which related the molecular weight and temperature of liquid polystyrene to its viscosity ${ }^{[25]}$

$$
\log \eta_{0}=3.4 \log M+[900.2 /(T-306.4)]-18.38
$$

where $\eta_{0}$ is the dynamic viscosity at zero shear rate, $M$ is the molecular weight, and $T$ is the temperature (in $\mathrm{K}$ ). 

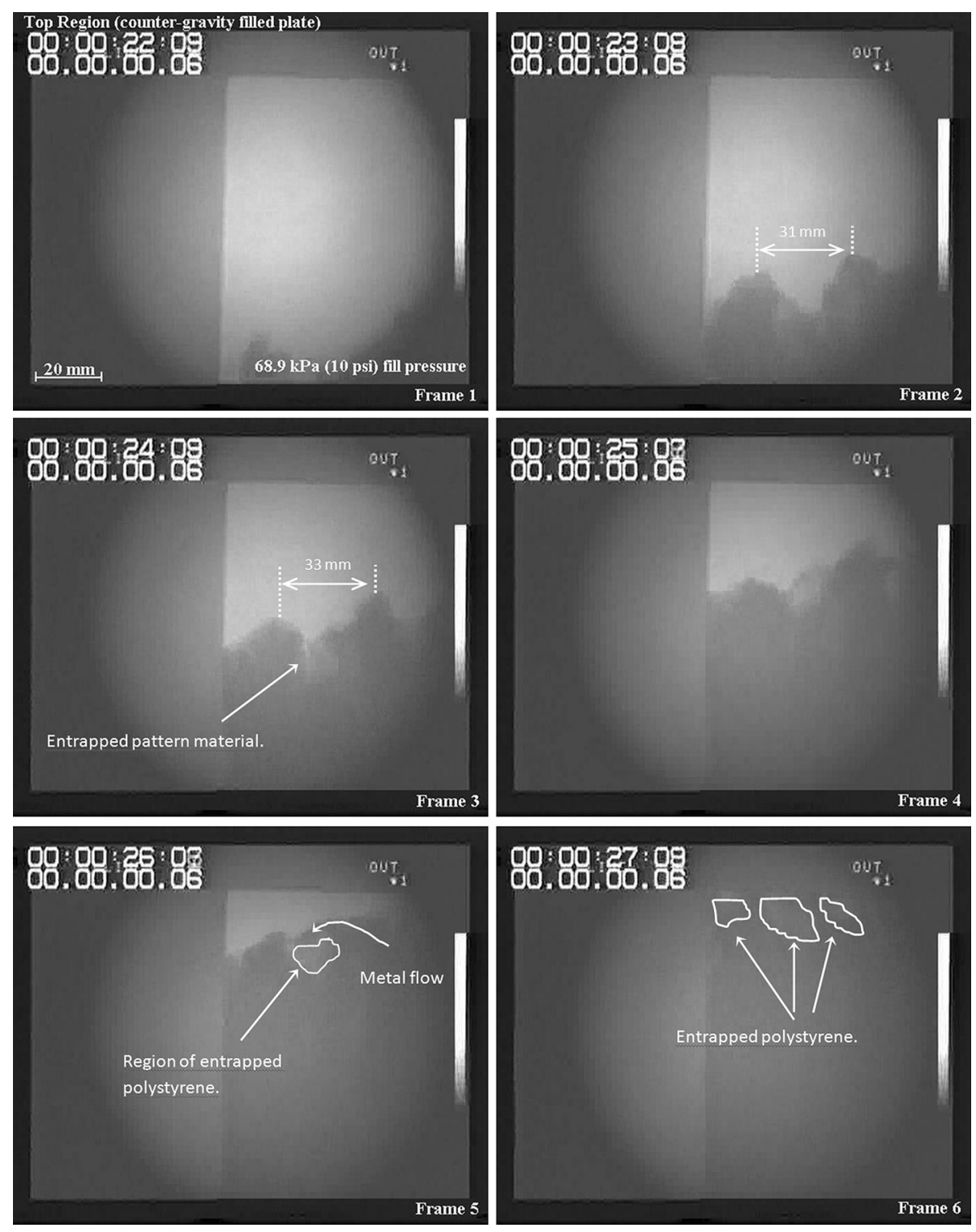

Fig. 7-Real-time X-ray images showing the morphology of the advancing liquid metal front, in an EPS pattern, during countergravity casting, filled with a chamber overpressure of $69 \mathrm{kPa}$.

This equation was originally devised for a temperature range of 448 to $503 \mathrm{~K}$ (175 to $230{ }^{\circ} \mathrm{C}$ ) ${ }^{[25]}$ but was subsequently shown to be applicable to a polystyrene melt at up to $703 \mathrm{~K}\left(430^{\circ} \mathrm{C}\right) \cdot{ }^{[26]}$ The mean temperature of the interface for which the viscosity was estimated was assumed to be the mean of the liquid metal and pattern temperatures, which was about $593 \mathrm{~K}\left(320^{\circ} \mathrm{C}\right)$.

\section{RESULTS}

\section{A. Castings Poured Under the Action of Gravity}

The filling of the top-gated plate has been shown in Figure 4, (with images taken at intervals of about $1 \mathrm{~s}$ ), and was associated with lobes of liquid metal advancing through the pattern, centimeters in size, resulting in the envelopment of the degrading pattern as the liquid metal lobes traveled downwards and coalesced. In addition, the individual lobes themselves showed smaller lobes at the metal-pattern interface, of a reduced size, (most clearly seen in Frames 1 and 2). In the bottom-gated casting, (Figure 5), the liquid metal front advancing upwards did not show the large lobes apparent in Figure 4, but did possess the smaller lobes seen in the top-gated casting. The wavelengths of these minor interfacial irregularities shown in Figure 5 were about $10 \mathrm{~mm}$ and about $2 \mathrm{~mm}$ in height.

Figure 6 shows a comparison of the distribution of tensile strength from the bottom-gated and top-gated plates. The top-gated arrangement, with its lobed advancing metal front, was associated with a Weibull Modulus of about 6, while filling the plate from the bottom, in which the smaller lobes only were seen, was associated with a slightly higher Weibull Modulus of about 9. Both Weibull Moduli values were relatively low. For example, in an open cavity casting process one 

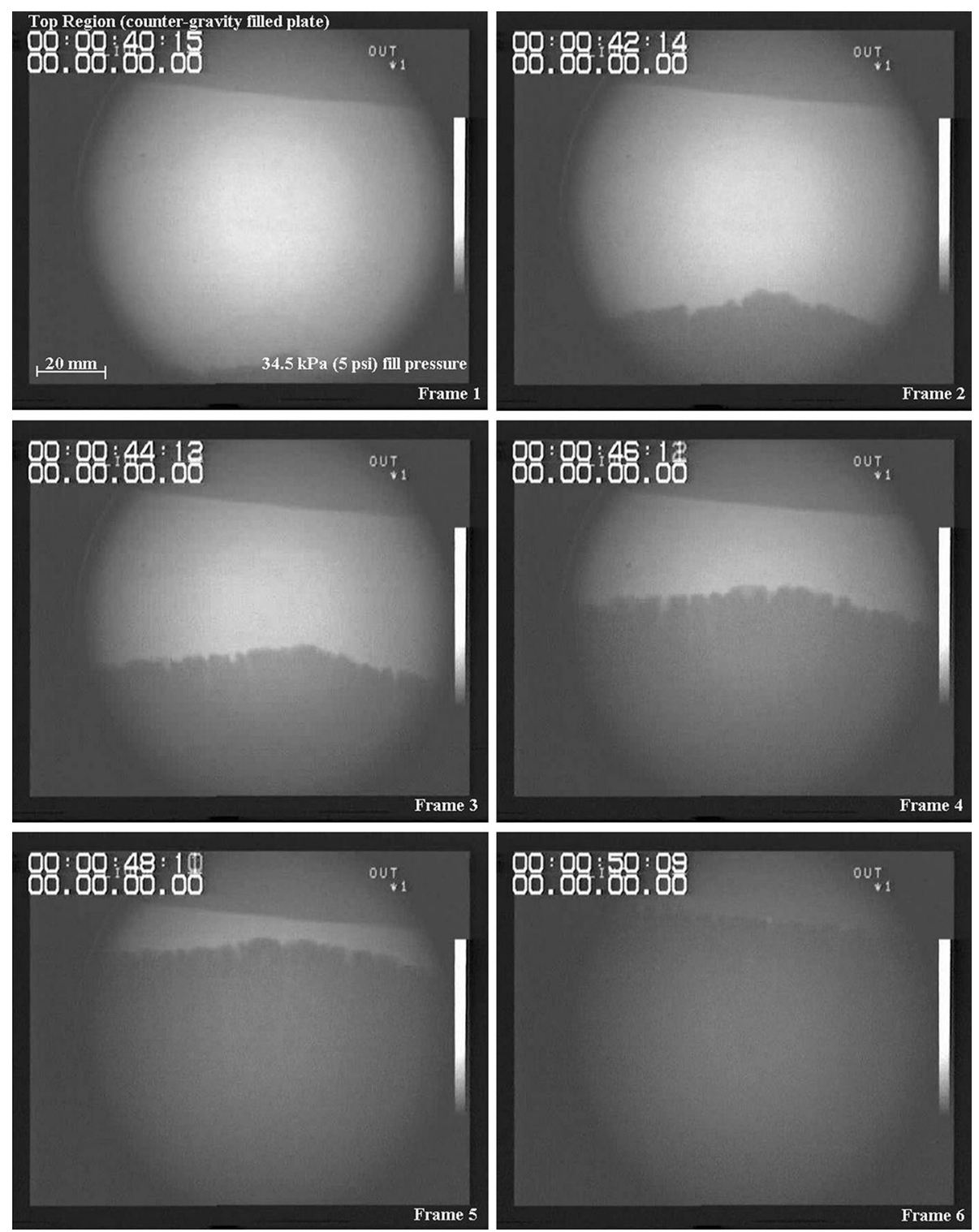

Fig. 8-Real-time X-ray images showing the morphology of the advancing liquid metal front, in an EPS pattern, during countergravity casting, filled with a chamber overpressure of $35 \mathrm{kPa}$, resulting in an approximate front velocity of $8 \mathrm{~mm} \mathrm{~s}^{-1}$.

might expect Weibull Moduli to vary from about 20, (indicating a relatively poor mold filling process), to about 40 , (indicating a mold filling process that introduced few or no defects). ${ }^{[27]}$ Examples of the types of defects found in these castings included relatively large $\mathrm{mm}$-sized porosity, and carbon-rich films that prevented fusion of the coalescing streams of the liquid metal.

\section{B. Countergravity-Filled Castings}

When the liquid metal was drawn up into the mold from below, the advancing liquid metal front showed a progressive reduction in the size of the irregularities at the liquid metal-pattern interface as the overpressure in the steel chamber was lowered, and the velocity of the advancing liquid metal was correspondingly reduced. For example, Figure 7 shows the advancing liquid metal front (at $2 \mathrm{~s}$ intervals) when the chamber overpressure was $69 \mathrm{kPa}$, and shows a very irregular metal front with extensive entrapment of the degrading polymer pattern. With a reduction of the overpressure in the chamber to $35 \mathrm{kPa}$, associated with a measured metal front velocity of about $8 \mathrm{~mm} \mathrm{~s}^{-1}$, the scale of the irregularity of the advancing liquid metal front was reduced to about $5 \mathrm{~mm}$ in wavelength and in height, (see Figure 8, images taken at varying intervals, at up to $10 \mathrm{~s}$ ). When the overpressure in the chamber was reduced to $28 \mathrm{kPa}$ the advancing liquid metal front had a lower velocity of about $5 \mathrm{~mm} \mathrm{~s}^{-1}$, and appeared planar, as shown in Figure 9. However, in this case the liquid metal solidified before it filled the mold completely, due to the low filling velocity.

Figure 10 shows a comparison between the Weibull Moduli obtained from the different filling conditions shown in Figure 5, (gravity-poured, bottom-gated), 8, and 9 , (countergravity-filled, at about 8 and $5 \mathrm{~mm} \mathrm{~s}^{-1}$, 

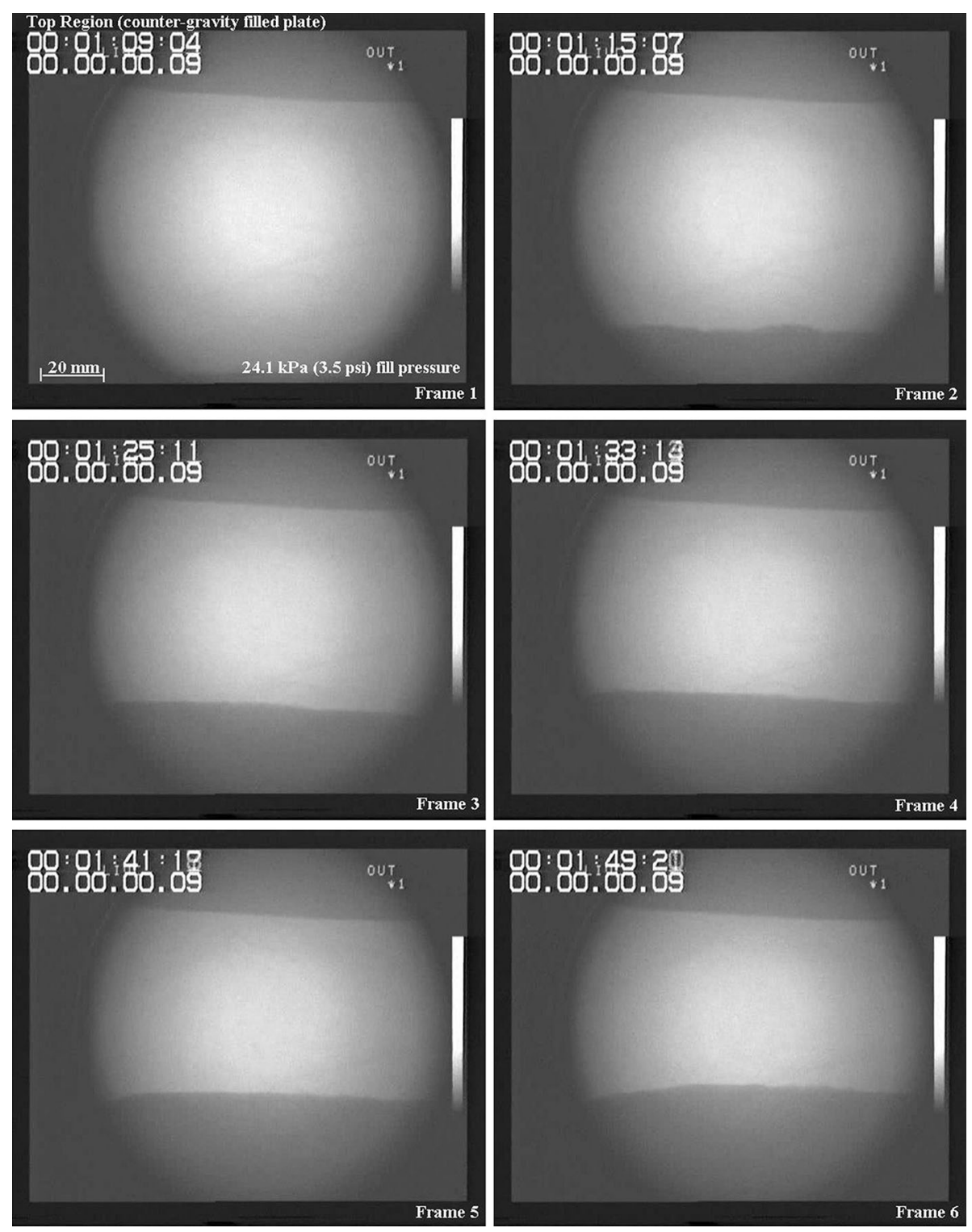

Fig. 9-Real-time X-ray images showing the morphology of the advancing liquid metal front, in an EPS pattern, during countergravity casting, filled with a chamber overpressure of $28 \mathrm{kPa}$, resulting in an approximate front velocity of about $5 \mathrm{~mm} \mathrm{~s}^{-1}$.

respectively). The bottom-filled castings and the countergravity-filled castings, which in both cases the real-time X-ray showed to have protrusions on the liquid metal-pattern interface, had low Weibull Moduli, of 9 and 11, respectively, while the casting with the planar advancing liquid metal front had a Weibull Modulus of 23.

Foamed polystyrene patterns were also cast which contained a $\mathrm{Br}$ additive, used to bring about quicker breakdown of the polystyrene degradation byproducts compared to a normal polystyrene pattern material (due to the $\mathrm{Br}$ cleaving molecular bonds). ${ }^{[28]}$ Figure 11 shows an advancing liquid metal front having a planar morphology, and moving at a velocity of about $5 \mathrm{~mm} \mathrm{~s}^{-1}$, similar to the casting shown in Figure 9. In comparison, Figure 12 shows the morphology of the liquid metal front as it advanced through the brominated pattern with a velocity of about $14 \mathrm{~mm} \mathrm{~s}^{-1}$. Some small perturbations in the liquid metal front were apparent, on a slightly larger scale than was observed in the case of the unbrominated patterns, (compare with Figure 8).

The Weibull Modulus results from the brominated plates cast in a countergravity fashion with a liquid metal front velocity of $5 \mathrm{~mm} \mathrm{~s}^{-1}$, (also resulting in a planar front), was 26, similar to that obtained with an unbrominated plate, and gave the highest Weibull Modulus obtained in these experiments. The Weibull Modulus results are also summarized in Table I.

\section{Molecular Weight Determinations of Degraded Polystyrene}

Gel Permeation Chromatography showed that the initial (Weight Average) molecular weight of the foamed polystyrene pattern material was $413,000 \mathrm{~g} \mathrm{~mol}^{-1}$, while for the foamed brominated polystyrene pattern material 


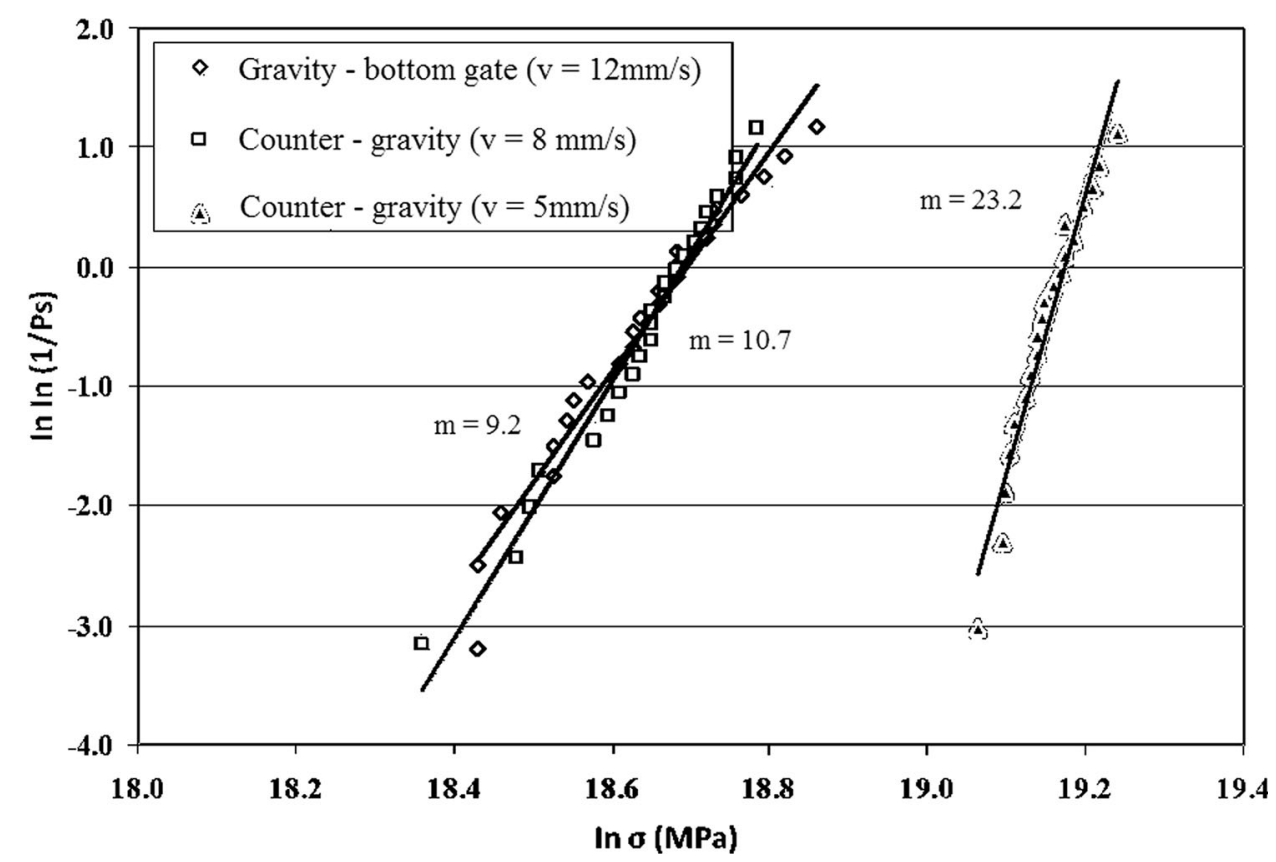

Fig. 10-Weibull plots of tensile test results from plates filled in a countergravity fashion. The results from the gravity-filled plates are from three plates cast with ingates at the bottom. The other two results are from single, countergravity-filled plates, filled at different velocities, 8 and $5 \mathrm{~mm} \mathrm{~s}^{-1}$, respectively.

it was $340,000 \mathrm{~g} \mathrm{~mol}^{-1}$. Exposure to heat from the liquid $\mathrm{Al}$ melt for around $5 \mathrm{~s}$ in the experiment shown in Figure 3 resulted in a reduction in the molecular weight of the polystyrene to around 70,000 to $180,000 \mathrm{~g} \mathrm{~mol}^{-1}$, (there was probably considerable variation in the heat received by the polymer sample owing to the simplicity of the experiment). Similarly, the brominated polystyrene sample experienced a reduction in its molecular weight to between about 40,000 to $170,000 \mathrm{~g} \mathrm{~mol}^{-1}$ under the same circumstances.

Applying Eq. [3] to these molecular weight values, and assuming an interface temperature of around $593 \mathrm{~K}$ $\left(320{ }^{\circ} \mathrm{C}\right.$ ), suggested dynamic viscosities (at zero shear rate), for the liquid polystyrene in the liquid metal-foam pattern interface of between about 14 to 6030 Pas, and values of between about 2 to 3100 Pas in the case of the brominated polystyrene. These values were only estimates of the viscosity of the liquid polymer degradation byproducts and can be interpreted as maximum values, as higher temperatures in the interface, and the presence of air and vapor pattern degradation byproducts, would greatly reduce the overall viscosity of the fluid in the metal-pattern interface.

\section{DISCUSSION}

The real-time X-ray images of the filling of the mold showed that a non-uniform advancing liquid metal front was associated with low Weibull Moduli, (with no value greater than about 11 being obtained), (see Figures 6 and 10). The highest Weibull Modulus, 23, was obtained when the liquid metal advanced with a planar front (see Figure 9). A higher Weibull Modulus was also obtained with brominated polystyrene pattern, exhibiting a planar advancing liquid metal front, (see Figure 11). In addition, real-time $\mathrm{X}$-ray radiography failed to show a gap between the advancing liquid metal and the degrading pattern, suggesting any such gap should be less than the dimension of the curvature of the advancing liquid metal front.

The morphology of the interface in the case of bottom-gated filling, (such as that seen in Figure 5), and countergravity filling, (see Figure 8), suggested that the interface was exhibiting an instability. In the case of liquid $\mathrm{Al}$, degradation of the polymer pattern is thought to mostly produce a liquid degradation byproduct, with the vapor degradation byproduct being much less. ${ }^{[4]}$ The mold is filled by a liquid metal traveling upwards, displacing the polystyrene pattern, which at the interface with the advancing liquid metal has probably degraded to a liquid consisting of short-chain polymer molecules, mixed with vapor, perhaps in the form of discrete bubbles.

The liquid $\mathrm{Al}$ alloy would have a density of about $2435 \mathrm{~kg} \mathrm{~m}^{-3}$, [29] and a dynamic viscosity of about $1 \times 10^{-3}$ Pas. $^{[29]}$ The properties of the polystyrene degradation byproducts are more difficult to estimate. The density of polystyrene foams for patterns is about 20 to $30 \mathrm{~kg} \mathrm{~m}^{-3}$, and the density of liquid polystyrene, (without any vapor bubbles present), is about $1000 \mathrm{~kg} \mathrm{~m}^{-3}$. ${ }^{30]}$ The density of the mixed liquid and vapor in the interface should therefore be somewhere between these values. If a 95 pct collapse of the foam is assumed, ${ }^{[31]}$ this would give a density of about $50 \mathrm{~kg} \mathrm{~m}^{-3}$. The viscosity of the liquid polystyrene in the interface was estimated to be between about 2 to 6000 Pas in the GPC experiments. In the 

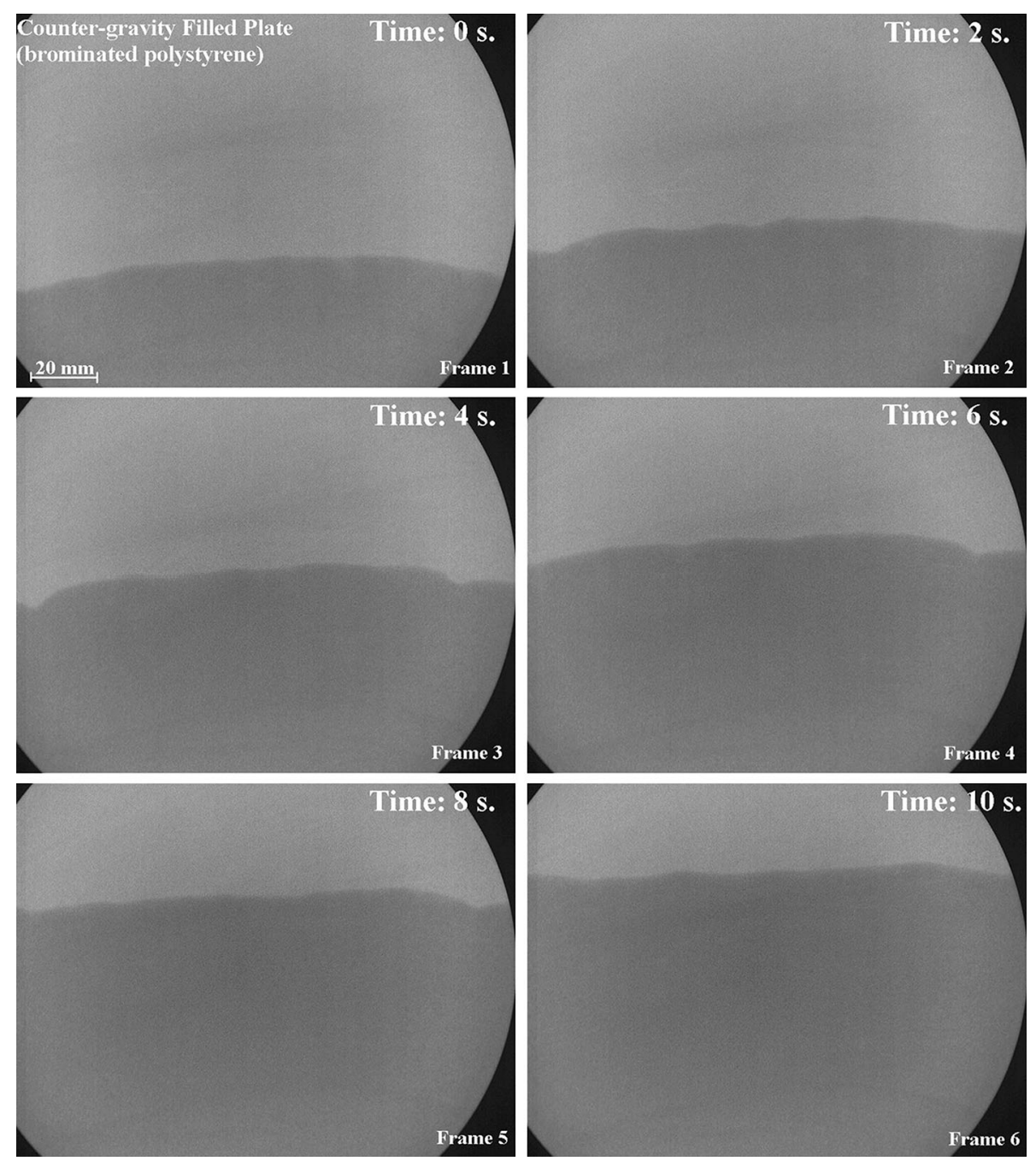

Fig. 11-Real-time X-ray images showing the morphology of the advancing liquid metal front during countergravity casting of a brominated EPS plate pattern, filled with an approximate front velocity of about $5 \mathrm{~mm} \mathrm{~s}^{-1}$.

countergravity-filled castings, the liquid metal-pattern interface therefore consisted of a high-density, low-viscosity liquid metal, advancing upwards into the pattern degradation byproducts, which consisted of a fluid with lower density, but higher viscosity. These are conditions that may be appropriate for the occurrence of Saffman-Taylor Instability.

This was studied by Saffman and Taylor for the case of flow between two parallel plates. ${ }^{[2]}$ They proposed that a critical velocity for initiation of Saffman-Taylor Instability for a moving interface between two fluids could be estimated from Eq. 4;

$$
V=\frac{-g\left(\rho_{2}-\rho_{1}\right)}{\frac{\mu_{2}}{\frac{b^{2}}{12}}-\frac{\frac{\mu_{1}}{12}}{12}},
$$

where $V$ is the velocity, $\mathrm{g}$ is the acceleration due to gravity, $\rho$ is the density, $\mu$ is the dynamic viscosity, and $b^{2} / 12$ is the permeability, (where $b$ is the distance between the two plates). Subscripts 1 and 2 refer to the lower and upper fluids, respectively, for a case where fluid 1 is less viscous than fluid 2, and fluid 1 is driven upwards into fluid 2. In the case of countergravity filling of the Lost Foam pattern, fluid 1 is then the liquid metal, and fluid 2 the polymer degradation byproducts.

For an estimated viscosity of the polymer degradation byproducts, in the case of EPS, of between 2 and $6000 \mathrm{Pas}$, and for a plate thickness of $10 \mathrm{~mm}$, a critical velocity for the onset of instability of between about 0.3 and $8 \mathrm{~mm} \mathrm{~s}^{-1}$, was estimated. For an estimated viscosity of the polymer degradation byproducts of between 2 and 300 Pas, (in the case of brominated EPS), the critical velocity for onset of the instability was estimated to be between about 0.4 and $59 \mathrm{~mm} \mathrm{~s}^{-1}$.

These values were comparable with the advancing metal front velocity observed by real-time X-ray, where the onset of instability was found to be between about 5 to $8 \mathrm{~mm} \mathrm{~s}^{-1}$, in the case of the EPS patterns, and between about 5 to $14 \mathrm{~mm} \mathrm{~s}^{-1}$, in the case of the brominated polystyrene patterns. In both cases, the velocities lay within the range of velocities estimated to be associated with the onset of Saffman-Taylor Instability. (However, these estimates greatly depend on the 

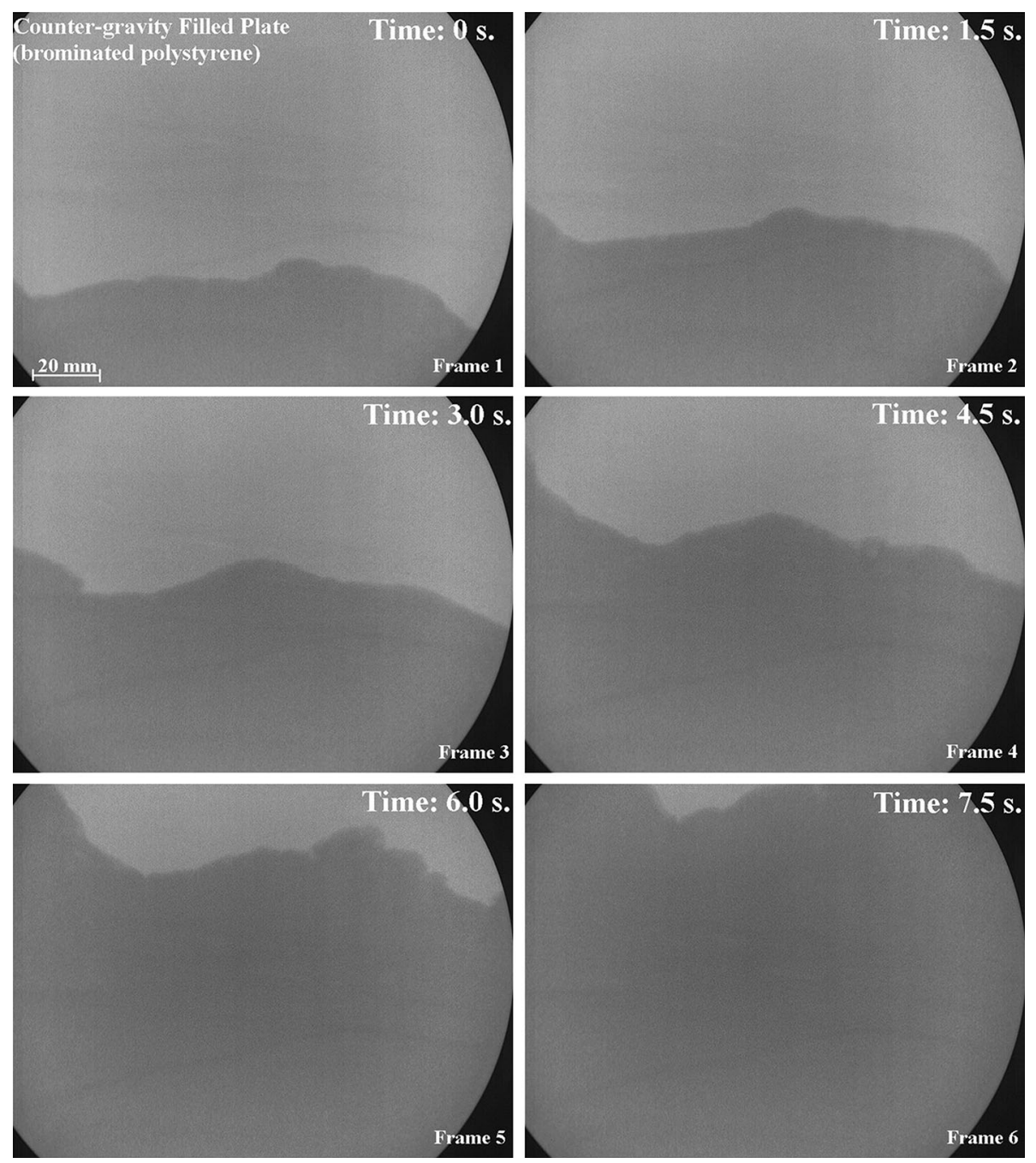

Fig. 12 - Real-time X-ray images showing the morphology of the advancing liquid metal front during countergravity casting of a brominated EPS plate pattern, filled with an approximate front velocity of about $14 \mathrm{~mm} \mathrm{~s}^{-1}$.

Table I. Summary of Weibull Results from the Casting Experiments

\begin{tabular}{llcr}
\hline Pattern Material & Casting Method & Interface Velocity (mm s ${ }^{-1}$ ) & Weibull Modulus (Tensile Strength) (MPa) \\
\hline Polystyrene & gravity cast (top-gated) & not measured & 6.2 \\
& gravity cast (bottom-gated) & 12 & 9.2 \\
& countergravity cast & 8 & 10.7 \\
& & 7 & 5.1 \\
Brominated polystyrene & countergravity cast & 6 & 23.2 \\
\hline
\end{tabular}

value assumed for viscosity of the polymer degradation byproducts.)

Other than Saffman-Taylor Instability, filling of Lost Foam molds may be associated with other hydrodynamic instabilities, creating other methods of entrapment of the degrading polystyrene pattern and reducing casting quality. For example, if the mold was poured from above, high-density liquid metal would descend through the lower-density fluid associated with the degrading pattern, and this may lead to RayleighTaylor Instability. ${ }^{[19,20]}$ If the liquid metal was advancing from a side-gate, passing horizontally through the pattern, the interface with the degrading pattern could lead to a case of Kelvin-Helmholtz Instability, as the 
gas in the interface would tend to escape vertically, parallel to the advancing interface.

To summarize, the presence of a polymer pattern degrading during casting into a fluid, leads to different phenomena during mold filling than are known from the filling of open cavity castings. In particular, it has been recognized that hydrodynamic instabilities can occur that could have a great effect on the entrapment of the degrading polystyrene and the formation of defects such as porosity and poor fusion of the different metal streams, due to the presence of carbon-rich films. Further consideration of the occurrence of hydrodynamic instabilities in Lost Foam casting could improve casting quality and the accuracy of simulations of this casting process.

\section{CONCLUSIONS}

1. Weibull Modulus estimates suggested that Lost Foam casting of $\mathrm{Al}$ can be associated with reduced uniformity of properties within a casting.

2. Real-time X-ray examination of the filling of vertically oriented foam pattern plates showed that the plates with the lowest values of Weibull Modulus and greater number of defects were associated with a non-uniform, unstable advancing liquid metal front.

3. Weibull Moduli values, similar to those associated with open cavity casting were achieved during countergravity filling of the polystyrene patterns using low-upward filling velocities.

4. The relative densities and viscosities of the liquid metal and polymer degradation byproducts at the liquid metal-pattern interface suggested that the interface could develop Saffman-Taylor Instability.

5. The velocity associated with the onset of Saffman-Taylor instability was estimated to be between about 0.3 to $8 \mathrm{~mm} \mathrm{~s}^{-1}$, in the case of an EPS pattern, and between about 0.4 and $59 \mathrm{~mm} \mathrm{~s}^{-1}$, in the case of brominated EPS patterns. These velocities are strongly dependent upon estimated values of the viscosity of the polymer degradation byproducts in the liquid metal-pattern interface.

6. The experimentally observed velocities associated with the transition from a planar to an unstable liquid metal front in the casting of Al alloys were found to fit within the range of possible estimates of the critical velocity for the onset of Saffman-Taylor Instability.

\section{ACKNOWLEDGMENTS}

The authors wish to acknowledge the financial support of GEMCO Engineers B.V., Park Eindhoven 5053, 5692 EB Son, The Netherlands, and the technical assistance of Adrian Caden of the School of Metallurgy and Materials, at the University of Birmingham, United Kingdom, B15 2TT.

\section{OPEN ACCESS}

This article is distributed under the terms of the Creative Commons Attribution 4.0 International License (http://creativecommons.org/licenses/by/4.0/), which permits unrestricted use, distribution, and reproduction in any medium, provided you give appropriate credit to the original author(s) and the source, provide a link to the Creative Commons license, and indicate if changes were made.

\section{REFERENCES}

1. S. Shivkumar, X. Yao, and M. Makhlouf: Scripta Met. et Mater., 1995, vol. 33, pp. 39-46.

2. X. Yao and S. Shivkumar: Mater. Sci. Technol., 1997, vol. 13, pp. $841-846$.

3. S. Shivkumar: Mater. Sci. Technol., 1994, vol. 10, pp. 986-992.

4. J. Yang, T. Huang, and J. Fu: AFS Trans., 1998, vol. 106, pp. $21-26$

5. M.H. Warner, B.A. Miller, and H.E. Littleton: AFS Trans., 1998, vol. 106, pp. 777-785.

6. T. Molibog and H. Littleton: AFS Trans., 2001, vol. 109, pp. $1523-1554$.

7. H.E. Littleton, B.A. Miller, D. Sheldon, and C.E. Bates: AFS Trans., 1996, vol. 104, pp. 335-346.

8. W.L. Sun, H.E. Littleton, and C.E. Bates: AFS Trans., 2002, vol. 110, pp. 1347-1356.

9. M. Sands and S. Shivkumar: J. Mater. Sci., 2003, vol. 38, pp. 667-673.

10. Y. Sun, H.L. Tsai, and D.R. Askeland: AFS Trans., 1992, vol. 101, pp. 297-308.

11. Q. Zhao, J.T. Burke, and T.W. Gustafson: AFS Trans., 2002, vol. 110, pp. 1399-1414.

12. W.D. Griffiths and P.J. Davies: Int. J. Cast Met. Res., 2011, vol. 24 , pp. 267-278.

13. D.A. Caulk: AFS Trans., 2007, vol. 115, pp. 833-844.

14. M.R. Barone and D.A. Caulk: Int. J. Heat Mass Transf., 2005, vol. 48 , pp. 4132-4149.

15. D.A. Caulk: Int. J. Heat Mass Transf., 2006, vol. 49, pp. 3831-3845.

16. D.A. Caulk: Int. J. Heat Mass Transf., 2006, vol. 49, pp. 2124-2136.

17. D.A. Caulk: AFS Trans., 2007, vol. 115, pp. 845-860.

18. M.J. Ainsworth and W.D. Griffiths: AFS Trans., 2006, vol. 114, pp. 222-236.

19. G.I. Taylor: Lond. Math. Soc., 1883, vol. 14, pp. 170-177.

20. L. Rayleigh: Philos. Mag., 1871, vol. 42, pp. 362-377.

21. HLF von Helmholtz: Monatsberichte der Königlichen Preussiche Akademie der (Monthly Reports of the Royal Prussian Academy of Philosophy in Berlin)Wiss. Berl., 1868, vol. 23, pp. 215-228.

22. P.G. Saffman and G.I. Taylor: Proc. R. Soc., 1958, vol. 245, pp. 312-329.

23. C. W Hirt and M. R. Barkhudarov, Flow Science Inc. Technical Notes, 1999, TN 45-1.

24. A. Khalili and K. Kromp: J. Mater. Sci., 1991, vol. 26, pp. 6741-6752.

25. W.P. Cox and R.L. Ballman: J. Appl. Polym. Sci., 1960, vol. 4, p. 121.

26. C. Diduch, R. Dubay, and W.G. Li: Polym. Eng. Sci. J., 2004, vol. 44 , pp. 2308-2317.

27. N.R. Green and J. Campbell: AFS Trans., 1994, vol. 102, pp. 341-347.

28. T.C. Pedersen: AFS Trans., 2006, vol. 114, pp. 887-898.

29. W. Kurz and D.J. Fisher: Fundamentals of Solidification, 3rd ed., Trans Tech Publications, Brookfield, 1992, p. 293.

30. J. Joshi, R. Lehan, and T. Nosker: J. Appl. Polym. Sci., 2006, vol. 99 , pp. 2044-2051.

31. P. Davies, PhD Thesis, University of Birmingham, 2007. 